\title{
PROGRESS REPORT: EVALUATION OF THERMALLY ACTIVE AREAS OF SOUTHWESTERN YELLOWSTONE NATIONAL PARK
}

\author{
R. A. Levinson and R. W. Marrs \\ Dept. of Geology, University of Wyoming \\ Laramie, Wyoming 82071
}

\section{Objectives}

Production from known geothermal areas adjacent to southwestern Yellowstone National Park could have an adverse impact on thermal activity, hydrology, and ecology within the Park. Such impacts cannot be determined without a more complete knowledge of thermal activity in the region. The purpose of this research is to 1) inventory thermal features in southwestern Yellowstone National Park and adjacent regions, 2) sample and analyze effluent from springs and natural waters in the area, and 3) assess the geologic structure of the region with regard to its influence on the thermal activity.

The proposed research program was funded for approximately one-third the requested amount. In order to allow the proposed work to begin without jeopardizing other research projects, we accepted the reduced funding with the understanding that the 1978-1979 research goals would be scaled down accordingly and that additional financial support might be made available if the initial results demonstrated the need for continuing the effort. Under the revised work plan, we limited our study to areas only within Yellowstone National Park. We also decided to concentrate on the inventory of thermally active areas and perform a preliminary assessment of geological structure observable at the surface. The thermal inventory and structural evaluation would be performed using remote sensor data. Detailed fieldwork involving geochemical sampling and gathering of ground truth data was postponed to be included in future research if results of our revised work plan prove positive.

\section{Procedure}

We began by identifying available maps, publications, and imagery for southwestern Yellowstone (see Table $I$ and "References"). A preliminary visit to Yellowstone National Park was made by Mr. Levinson in June, 1978. He spoke with research biologists and with Mr. Hutchinson, park geologist, and determined the location and nature of known thermal activity in the area. He also spoke with Mr. Susong, district ranger, for the Bechler region and gathered specific information about the study area and current field conditions.

Thirteen areas of thermal activity had been previously identified in southwestern Yellowstone (Hutchinson, 1977). Thermal features in these known areas include hot and warm springs, turbid springs, thermal pools, seeps, hot steaming ground, fumaroles, and mudpots. Only one active geyser has been identified in the area. Locations of these known thermal 
areas are shown in figure 1. Detailed descriptions of these areas, including temperature and discharge measurements, are presented by Hutchinson (1977). Keefer (1971) discusses the relationship between thermal features and fracture zones, and how faults and joint systems may serve as conduits for circulation of hydrothermal solutions. Major faults in the area are shown on the geological map of Yellowstone National Park (U.S. Geological Survey, 1972). Stratigraphic relationships of volcanic and sedimentary rocks in the region are described by Christiansen and Blank (1972). These known thermal areas and geologic features served as training sites from which remotely sensed data could be evaluated.

\section{Image Analysis}

Using remote sensor data, large areas can be inventoried quickly at modest cost. Various sensors detect different portions of the electromagnetic spectrum and produce image data from different viewing altitudes. To date, several types of imagery have been used to evaluate the study area for thermal potential. These include: aerial thermography, color and color infrared aerial photography, and black-and-white orthophotography.

\section{Thermography}

We obtained a thermographic mosaic of Yellowstone National Park (University of Michigan, Institute of Science and Technology, 1969). These data were acquired near midnight on April 9-10, 1969, from a flight elevation above mean terrain (amt) of $5,487.8 \mathrm{~m}$. Snow cover in the park was near annual maximum at that time. Thermally active areas were not snowcovered and contrast sharply with non-thermal, snow-covered areas. Areas emitting high amounts of thermal radiation appear light-toned on the mosaic. Large thermal features, such as the geyser basins and warm rivers, could be easily recognized. Individual geysers or hot springs could be detected only if they had an adequate surface expression (on the order of $100 \mathrm{sq} . \mathrm{m}$ ) and sufficient thermal contrast with their surroundings. Most of the known sites of thermal activity could be identified only with previous knowledge of their locations. Similar lighttoned areas are visible on the imagery, but these "anomalies" could be caused by system noise, dust, or reproduction defects, or they could represent real thermal activity. The distinction could not be made on the poor quality thermal representation of the mosaic.

The imagery from which the mosaic was compiled was also acquired (courtesy of U.S. Geological Survey). These scenes were enlarged and contrast stretched on the video image analysis system at the University of Wyoming Remote Sensing Laboratory (Levinson, Marrs, and Grantham, 1976). The preliminary results of the video analyses were largely unsuccessful. Large thermal features could still be recognized and more small features within large thermally active areas could be identified. Again, light- 
toned anomalies which appear similar to known thermal features could be recognized. However, due to image processing noise and reproduction defects, the origin of anomalous areas could not be positively determined.

There are major problems with the quality of this thermal imagery. Ramp distortion (darkening of the film toward the edges) is quite pronounced. This makes tonal interpretation and image density contouring impossible. There are also many scratches and film processing stripes running lengthwise on the film. Because of the small scale of the original imagery, enlargement of the thermography was necessary to see detail. However, enlargement of the images also emphasized scan-striping, dust marks, and processing noise such that it became a hindrance to image interpretation. Quantitative thermal measurements of the recognizable thermal features could not be made because blackbody and graybody calibration stripes were not provided.

\section{Aerial Photography}

A preliminary photo interpretation of the study area was made from high altitude, 1:120,000-scale aerial photography flown by NASA in August, 1969 (Mission 101, Lines 1 and 2). This photography was available in both color and color infrared films. Both film types were severely underexposed. The resulting darkening of the $f i l m$ together with the small scale make this coverage inadequate for interpretation of thermal features other than large thermal areas (all of which are known).

Analysis of this photography did show that hydrothermal deposits (travertine, geyserite) possess a high albedo in the visible and near infrared wavelengths. This makes them appear as extremely bright areas on aerial photographs. In the Yellowstone region, the very bright areas are unique to the thermally active zones; thus, they can be used as an indicator of thermal activity. This technique is not applicable to thermal areas not associated with hydrothermal deposits.

\section{Orthophotography}

Orthophoto quadrangles present photographic information in a geometrically corrected form that is planimetrically adjusted to correspond to

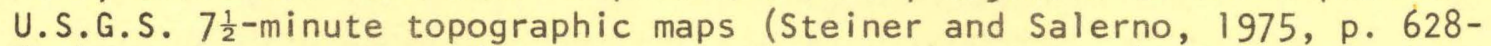
629). Advance prints (screened imagery on diazo paper) of five 1:24,000scale orthophoto quads, covering the southern and western portion of the study area, are available from the U.S.G.S. These were originally prepared from 1:80,000-scale black-and-white aerial photographs taken on September 2 and 18, 1974. The scale of this coverage was superior to the Mission 101 photography, and several of the known thermal areas could be recognized. However, the tonal reproduction on these advance prints is poor, making them unsuitable for assessment of small thermal areas. All light-toned areas appeared similar; hydrothermal deposits 
were not uniquely identifiable. This may be, in part, due to the quality of the orthophoto advance prints. It might also be that hydrothermal deposits have a unique spectral contrast that is best seen on color or color infrared films. These films record information in discrete spectral bands. For example, color films may be color separated into blue, green, and red bands. Only when all individual bands are used can hydrothermal deposits be distinguished from other light-toned areas which may appear identical on panchromatic (black-and-white) photography.

New Data Available

New image data have recently been made available to us by the U.S. Geological Survey enabling the image analysis process to continue. These new data include new thermal scanner data (Table I, NASA, 1966), which covers selected sites within the park, and side-looking airborne radar (SLAR) imagery (Table 1, Westinghouse, 1965), which covers most areas within the park. The SLAR imagery should be especially valuable for interpretation of structural geology in the study area.

We are aware of other coverage of the study area from which we would like to make interpretations if those data are made available to us. The Park Service has on file high-quality, low-altitude 1:16,400-scale color photography (ETZ Series, 1969-1971). Thermal areas have been successfully identified in other areas of the park from this coverage (Levinson and Marrs 1978, Plate 1). Thermal image data from the Heat Capacity Mapping Mission (HCMM) thermal satellite should become available for the first time during the next few months. HCMM was placed in an orbit such that a particular area on the ground is covered both at night and at mid-afternoon, thus enabling thermal inertia images to be generated. The broad resolution of HCMM (.5 km on the ground) may limit its usefulness as a data base for assessment of small thermal areas. HCMM data may, however, show broad thermal patterns which cannot be detected on largescale imagery.

\section{Summary of Results to Date}

1. A preliminary inventory of thermally active areas in southwestern Yellowstone National Park has been accomplished using available airborne thermography.

2. Several light-toned anomalous areas have been identified on thermography which may or may not represent new (previously unknown) thermal areas. This interpretation has yet to be fully evaluated.

3. Analysis of color and color infrared aerial photography has shown that thermal areas can be recognized in the visible and near infrared wavelengths based on the high albedo of associated hydrothermal deposits.

4. Assessment of thermal activity using high-altitude, color and color 
infrared photography was unsuccessful because of the poor quality and small scale of the available coverage.

5. Analysis of quad-centered orthophotography suggests that panchromatic photography may be inferior to color and color infrared photography for identification of hydrothermal deposits associated with thermal areas.

Current Work Plan

\section{Work Item}

Analyze new thermal scanner data

Analyze SLAR imagery

Analyze ETZ series aerial photography

Analyze HCMM data

Interpret thermal occurrences and structural geology. Construct maps.

Compile final report with recommendations for future work.

\section{Planned Completion Date}

Jan. 15 - Jan. 31

Feb. 1 - Feb. 15

Feb. 16 - Mar. 15

Mar. 16 - Mar. 31

Apr. 1 - Apr. 30

May 1 - May 30

\section{Acknowledgments}

We wish to thank personnel of Yellowstone National Park for their assistance, especially Mr. Roderick Hutchinson. We also wish to thank personnel at the U.S. Geological Survey at Denver, Colorado for making thermal data available to us. This study was supported through a grant from the Northern Rocky Mountain Parks Studies Cooperative Program.

\section{References}

Christiansen, R.L., and Blank, H.R. Jr., 1972, Volcanic stratigraphy of the Quaternary rhyolite plateau in Yellowstone National Park; U.S. Geological Survey Prof. Paper 729-B, 18 p.

Hutchinson, R., 1977, Backcountry thermal survey of Southwestern Yellowstone National Park; National Park Service "in-house report", Yellowstone National Park, Mammoth, Wyoming.

Keefer, W.R., 1971, The geologic story of Yellowstone National Park; U.S. Geological Survey Bull. 1347, $92 \mathrm{p}$.

Levinson, R.A., and Marrs, R.W., 1978, The use of remote sensing for establishing a history of forest fires in Yellowstone National Park; Final Report on National Park Service contract CX-1200-7-B033, 48 p.

Levinson, R.A., Marrs, R.W., and Grantham, D.G., 1976, Rapid, low-cost image analysis through video processing; U.S. Dept. of Energy (for- 
merly ERDA) Open File Report GHBX-37(76), 54 p.

Steiner, D., and Salerno, A.E., 1975, Remote sensor data systems, processing, and management; Manual of Remote Sensing, Reeves, R.G., ed., American Society of Photogrammetry, Falls Church, VA., P. 611803.

U.S. Geological Survey, 1972, Geologic map of Yellowstone National Park; Misc. Geological Investigations Map 1-711, 1:125,000.

University of Michigan Institute of Science and Technology, 1969, Thermographic mosaic of Yellowstone National Park, Wyoming, Idaho, and Montana; available through U.S. Geological Survey, EROS Data Center, Sioux Falls, S.D. 


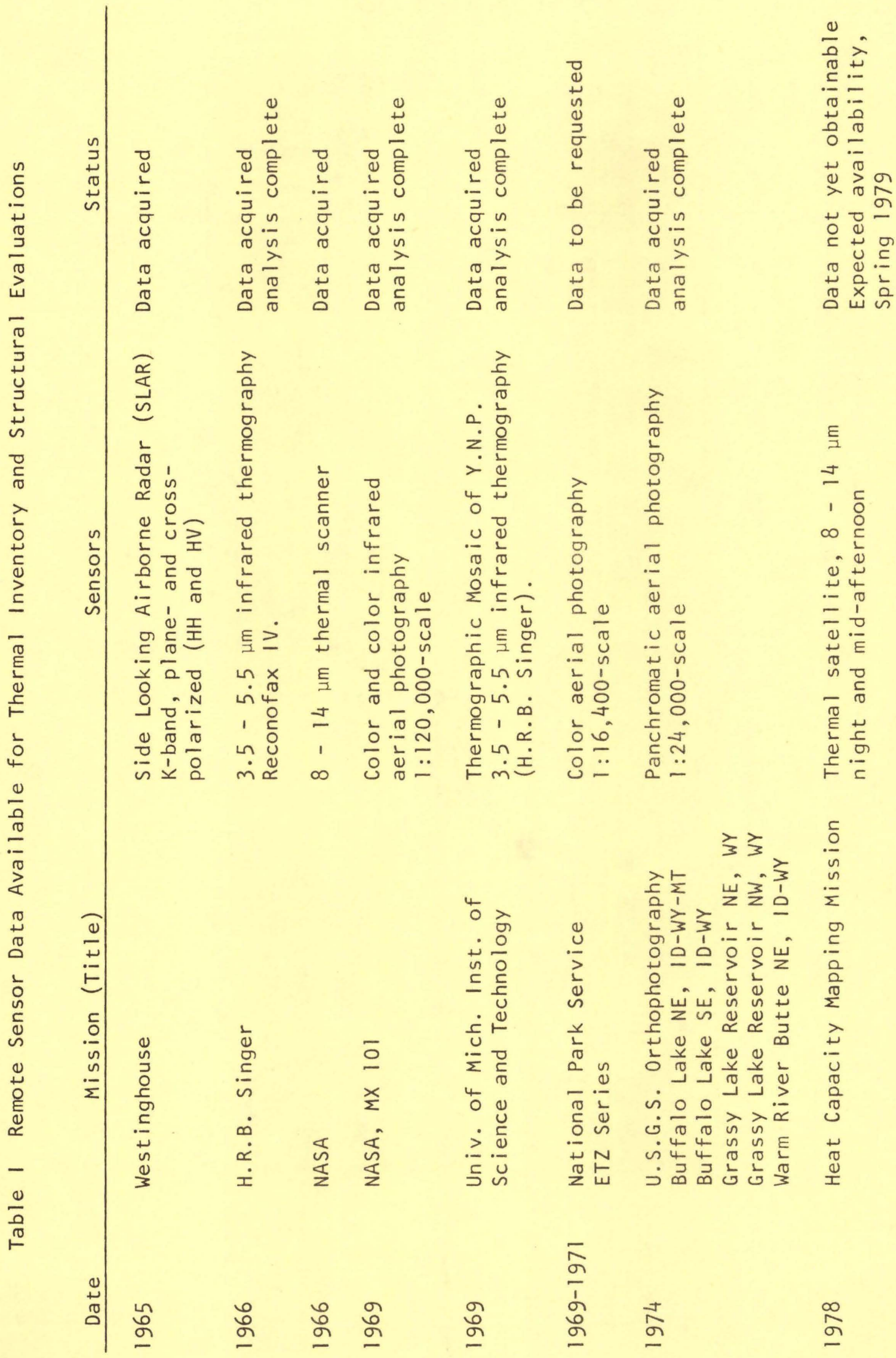




\section{KNOWN THERMAL AREAS IN SOUTHWESTERN YELLOWSTONE NATIONAL PARK}
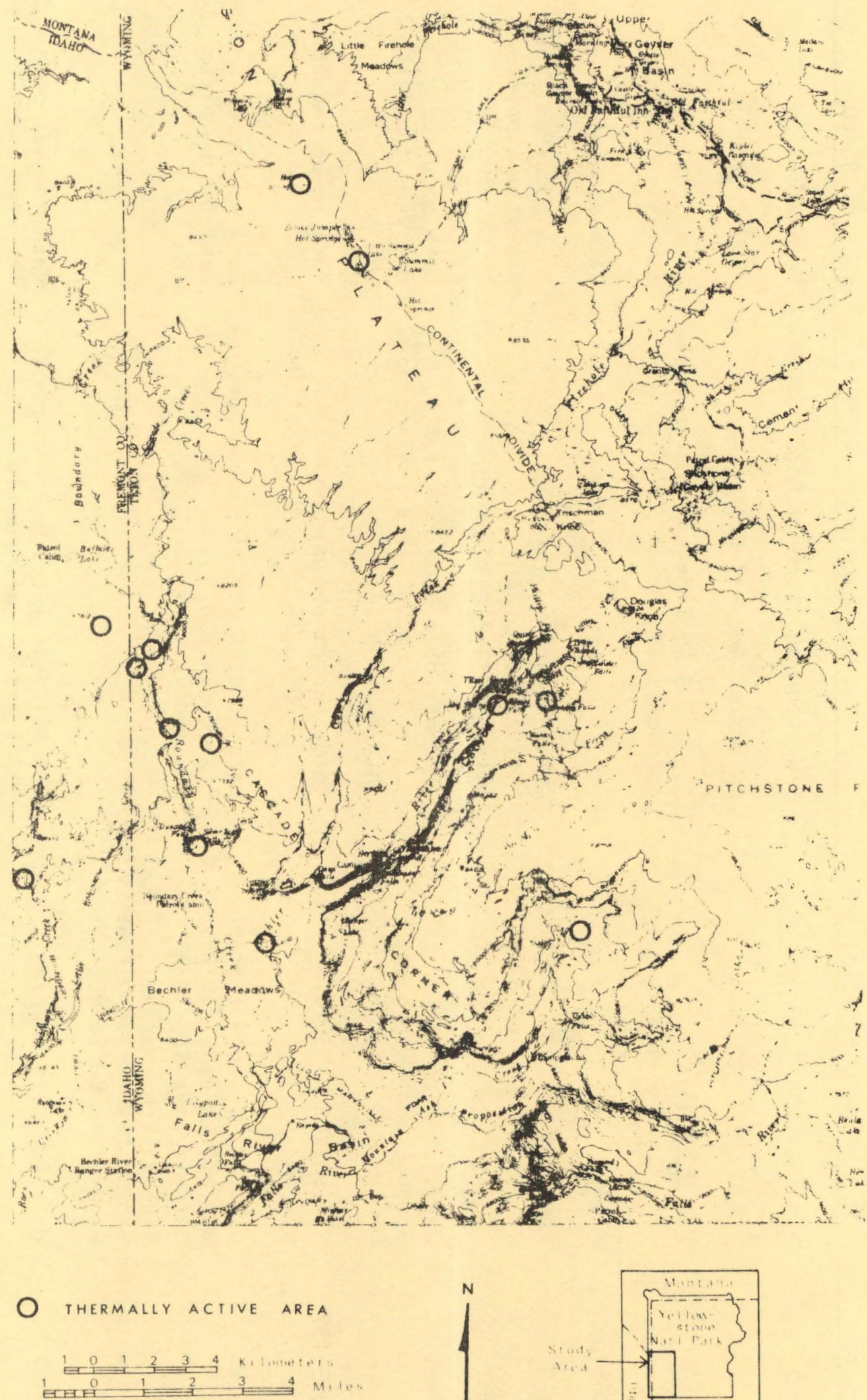

Base Map: Yellowstone national Park

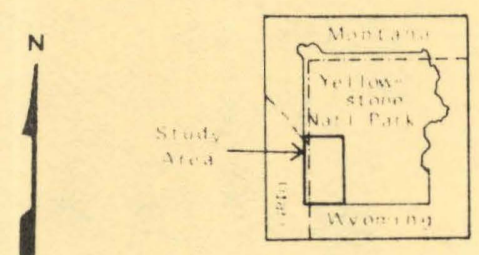

WYO, -MONT, - IDAHO. 1961

U.S.G.S. $1: 250,000$ - Scale Topographic Map

CONTOUR INTERVAL: 80 FEet 